\title{
Comamonas kerstersii strains on inpatients with acute appendicitis: Review of literature and case report
}

\author{
Galo Guillermo Farfán-Cano ${ }^{1}$ \\ Jorge Alberto Sarmiento Bobadilla² \\ Jara León Erick Alexander ${ }^{2}$ \\ Cindy Marianella Crespo Díaz ${ }^{3}$ \\ Glen Andrés Silva-Rojas ${ }^{3}$ \\ María Tarcila Solórzano Bravo 4 \\ Henry Junior Parra Vera ${ }^{5}$ \\ Luis Alberto Chantong Villacres ${ }^{6}$ \\ Kevin Joshua Silva-Rojas ${ }^{3}$
}

\section{$\underline{\text { ABSTRACT }}$}

In this article, we describe 6 cases of patients that presented to the emergency room with symptoms and laboratories compatible with the diagnosis of acute appendicitis. What attracts attention about these six cases are the results of the culture of the tissue, which reveals in these six patients the presence of the bacteria Comamonas kerstersii.

Indexing Terms: Intraabdominal Infections; Appendicitis; Comamonas;

\footnotetext{
${ }^{1}$ Society of Infectious Diseases of Guayas (SIG), University of Guayaquil, General Hospital of the North of Guayaquil Los Ceibos, Avenida 10 NO, Guayaquil 090613, Equador. Correspondence to: GG Farfán-Cano. E-mail: <galofarcan@gmail.com>.

${ }^{2}$ Catholic University of Santiago de Guayaquil, General Hospital of the North of Guayaquil Los Ceibos. Guayaquil, Equador

${ }^{3}$ Catholic University of Santiago de Guayaquil.

${ }^{4}$ Society of Infectious Diseases of Guayas (SIG). Pontifical Catholic University of Argentina.

${ }^{5}$ Society of Infectious Diseases of Guayas (SIG), University of Guayaquil. General Hospital of the North of Guayaquil Los Ceibos Microbiological Research Center (CIM).

${ }^{6}$ University of Guayaquil. Catholic University of Santiago de Guayaquil. General Hospital of the North of Guayaquil Los Ceibos.
}

Como citar este artigo / How to cite this article

Farfán-Cano GG, Bobadilla JAS, Alexander JLE, Díaz CMC, Silva-Rojas GA, Solórzano Bravo MR. Comamonas kerstersii strains on inpatients with acute appendicitis: review of literature and case report. InterAm J Med Health 2021;4:e202101016. https://doi.org/10.31005/iajmh. v4i. 165 


\section{INTRODUCTION}

The etiology of appendicitis includes parasites or inflammatory lymphoid hyperplasia, but the most common is undoubtedly the presence of fecaliths, which produce obstruct the lumen of the cecal appendix, increasing intraluminal pressure and consequent secondary inflammation, which determines the decrease in venous return locally and the subsequent compromise of arterial flow. The diagnosis of acute appendicitis is a challenge where, despite the use of biomarkers and imaging studies, where the clinical history plays a fundamental role [1-5].

The genus Comamonas originally described in 1985, with a single species, Comamonas terrígena, is composed of non-fermenting gram-negative bacilli, they are common bacteria in the environment, usually considered as lowvirulence organisms, their poor diagnosis as infectious agents, it is attributed to the limited capacity of automated phenotypic equipment; C. terrígena comprises three different groups of DNA hybridization, whose genotypic and phenotypic differences indicate that they are different species (Comamonas terrigena DNA group 1, Comamonas aquatica DNA group 2 and Comamonas kerstersii DNA group 3) [6-9].

In 1987 the species Pseudomonas acidovarans (which was subsequently reclassified in 1999 based on its 16S rRNA gene sequence, such as Delftia acidovarans) and Pseudomonas testosteroni, within the genus Comamonas were reclassified [6-8].

\section{CASE REPORT}

\section{Case 1}

A 14-year-old boy presented to de ER with a 3-day history of abdominal pain, first located in the epigastrium, then in the periumbilical area, and finally located in the right lower quadrant. Additionally, he had fever (380C) and had vomited in four occasions. The patient was evaluated and diagnosed with peritonitis associated to appendicitis. Laparoscopic surgery was performed, where the surgeon found a gangrenous cecal appendix with perforated base and $200 \mathrm{ml}$ of purulent peritoneal fluid, which was sent to the microbiology laboratory to be studied. The patient received empiric antibiotic treatment with ceftriaxone, metronidazole and amikacin, but after 5 days, considering the slow recovery of the surgical wound, antibiotics were changed to piperacillin/tazobactam, as indicated by the infectiology department.
In the peritoneal liquid the microorganism Comamonas kerstersii was isolated. Considering the slow recovery of the surgical wound, Piperacillin/Tazobactam was maintained for 14 days and amikacin was administered for 7 more days. Finally, the patient was discharged after being hospitalized for 30 days with a favorable progress of his surgical wound, without complications.

\section{Case 2}

A 27-year-old young woman with a history of obesity and being in lactation period presented to the emergency department with 24-hour history of abdominal pain of great intensity that was located at first at the mesogastrium but then migrated to the lower right quadrant; associated to nausea and vomit. After being assessed by a surgeon, the patient was diagnosed with acute appendicitis. An exploratory laparotomy + appendectomy was performed where the surgeon found the caecum located in the right flank, cecal appendix stage II of retrocecal location, appendicular base unscathed and approximately $50 \mathrm{ml}$ of purulent liquid in area near appendix. A tissue sample was taken for culture by the microbiologic laboratory.

The patient received ciprofloxacin and metronidazole IV for 10 days. Upon completing antibiotics and presenting a favorable progress of the surgical wound, patient was released from the hospital.

The microbiological report of the tissue culture reported Escherichia coli and Comamonas kerstersii.

\section{Case 3}

A 29-year-old male patient, without history of relevancy presents to the ER with 12-hour history of abdominal pain located in the hypochondrium and right side of the abdomen. A peripheral venous blood sample taken at admission showed white blood cell count $14.1 \times 103 /$ ul. The patient undergoes conventional appendectomy, where the surgeon found $100 \mathrm{ml}$ of inflammatory liquid and a phlegmonous appendix which was not perforated. A tissue sample was taken by the microbiology department. This patient received ciprofloxacin and metronidazole during his hospitalization. 72 hours later patient was discharged considering his prompt recovery, continuing the medication at home. No complication was reported during his controls.

The microbiological report of the tissue culture reported Escherichia coli and Comamonas kerstersii. 


\section{Case 4}

A 68-year-old male patient, without relevant history, presents to the emergency department with 3-day history of abdominal pain, which located at the epigastrium but moved afterwards to the lower right quadrant. The patient had taken analgesics and proton pump inhibitors without medical prescription. After being inspected and evaluated by the hospital personnel, the patient underwent a diagnostic laparoscopy and subsequently a laparoscopic appendectomy. A tissue sample was taken by the microbiological department for culture. The patient stayed in the hospital for 24 more hours, and since he did not present any sings of complications was sent home. No complications were reported in subsequent controls.

In the culture of the tissue sample taken from the appendix, a Comamonas kerstersii was isolated along with Escherichia coli.

\section{Case 5}

A 16-year-old girl, without relevant history, presents to the emergency room with a 24-hour history of abdominal pain, at first located in the mesogastrium that moved toward the right lower quadrant accompanied by nausea, vomit and fever. A peripheral venous blood sample taken at admission showed white blood cell count 10.6 x 103/ul with neutrophil count $9.46 \times 103 / u l$. After initial assessment, the patient was diagnosed acute appendicitis and a conventional appendectomy was performed. During surgery they found $200 \mathrm{ml}$ of inflammatory liquid and a fibrinopurulent retrocecal appendix. A tissue sample was taken by the microbiology department. The patient received ampicillin/sulbactam + metronidazole during her hospitalization period. 24 hours after the surgery the patient is discharged from the hospital. No complication was reported during subsequent controls.

In the culture of the tissue sample taken from the appendix, a Comamonas kerstersii was isolated along with Escherichia coli.

\section{Case 6}

EA 16-year-old girl with history of psoriasis, presents to the emergency department with a 32-hour history of diffuse abdominal pain, which located later in the right lower quadrant accompanied by nauseas, vomit and fever. Before presenting to the emergency department the patient had taken some analgesics and antibiotics. A peripheral venous blood sample taken at admission showed white blood cell count $19.4 \times 103 /$ ul with neutrophil count $16.3 \times 103 /$ ul. After assessment, the diagnosis of acute appendicitis was made, so a conventional appendectomy was performed on the patient. During surgery, $200 \mathrm{ml}$ of inflammatory liquid was found along with a plastronated appendix. A tissue sample was taken by the microbiology department for culture. The patient received ampicillin/ sulbactam for antimicrobial therapy. 24 hours after the surgery, considering her prompt recovery, she was discharged from the hospital. No complication was reported during subsequent controls.

In the culture of the tissue sample taken from the appendix, a Comamonas kerstersii was isolated along with Escherichia coli.

\section{METHODS AND RESULTS}

The methodology used by the microbiology lab. for identification of species, was carried out-based on obtaining the strains from the precipitate obtained from the different samples. First, sowing was carried out in traditional culture methods (blood agar, MacConkey agar, and chocolate agar), all were grown at a temperature of $35 \pm 2^{\circ} \mathrm{C}$ for approximately $24-48$ hours until the growth of colonies. Once the colonies were obtained, they were processed by the PHOENIX automated system, which gave the preliminary diagnosis of Comamonas testosteroni.

Since this system does not have other species of Comamonas in its registry, it does not allow to elucidate the diagnosis of other species of this genus. With the preliminary result of $\mathrm{C}$. testosteroni, we proceeded to analyze the strain from the colonies, using MALDI-TOF MS, preparing the strains in wells, letting dry, once the strains of the wells were dried, Matrix was added and let dry again. This process was carried out with each of the samples received, to finally obtain the result of Comamonas kerstersii, in each one of the isolates the Spectral Score was superior to 2,8.

\section{DISCUSSION}

C. kerstersii is a nonfermenting betaproteobacterium, Gram-negative, oxidase and catalase-positive bacteria, that are motile largely because of the presence of polar flagella, that was described as an individual species in 2003, after sequencing analysis of the 16s rRNA, recognized as 
a phytopathogen, widely distributed in the environment (water, soil, and plants) has the ability to survive in aquatic environments, which makes it an opportunistic pathogen for humans; has recently been associated with intraabdominal infection due to perforation of the digestive tract $[6,8,10-11,13]$.

It has been described that some of the isolates identified as C. testosteroni may have been C. kerstersii, and that the absence of species identification is due to many automated systems, mostly phenotypic identification, only have two types in their records Comamonadaceae (C. acidovarans and C. testosteroni), an example of these biases in the identification of these microorganisms, is offered by Yun-heng et al. 2018, in which case report the microorganisms were identified primarily with $B$. bronchiseptica [7]. A similar case is that of Barbaro et al. 1987, who identified 10 cases of appendicitis perforated by $C$. testosteroni through the Vitek system, which does not have a record of $C$. kerstersii in its database $[7,8]$.

Since 2013, there have been several articles reporting intraabdominal infections in which Comamonas kerstersii was involved, with only one patient that presented a nonintraabdominal infection, reported by Almuzara et al. 2018, which had a urinary tract infection $[12,13]$.

The CLSI manual was reviewed, in which no results were found regarding the MIC necessary to consider that there is resistance or sensitivity on the part of Comamonas to antimicrobial strains $[14,15]$.

We describe in Table 1 a comparison of diagnosis methods used for identification of species, MALDI-TOF spectral score obtained and coinfection with another microorganisms reported, between the different cases reported in literature.

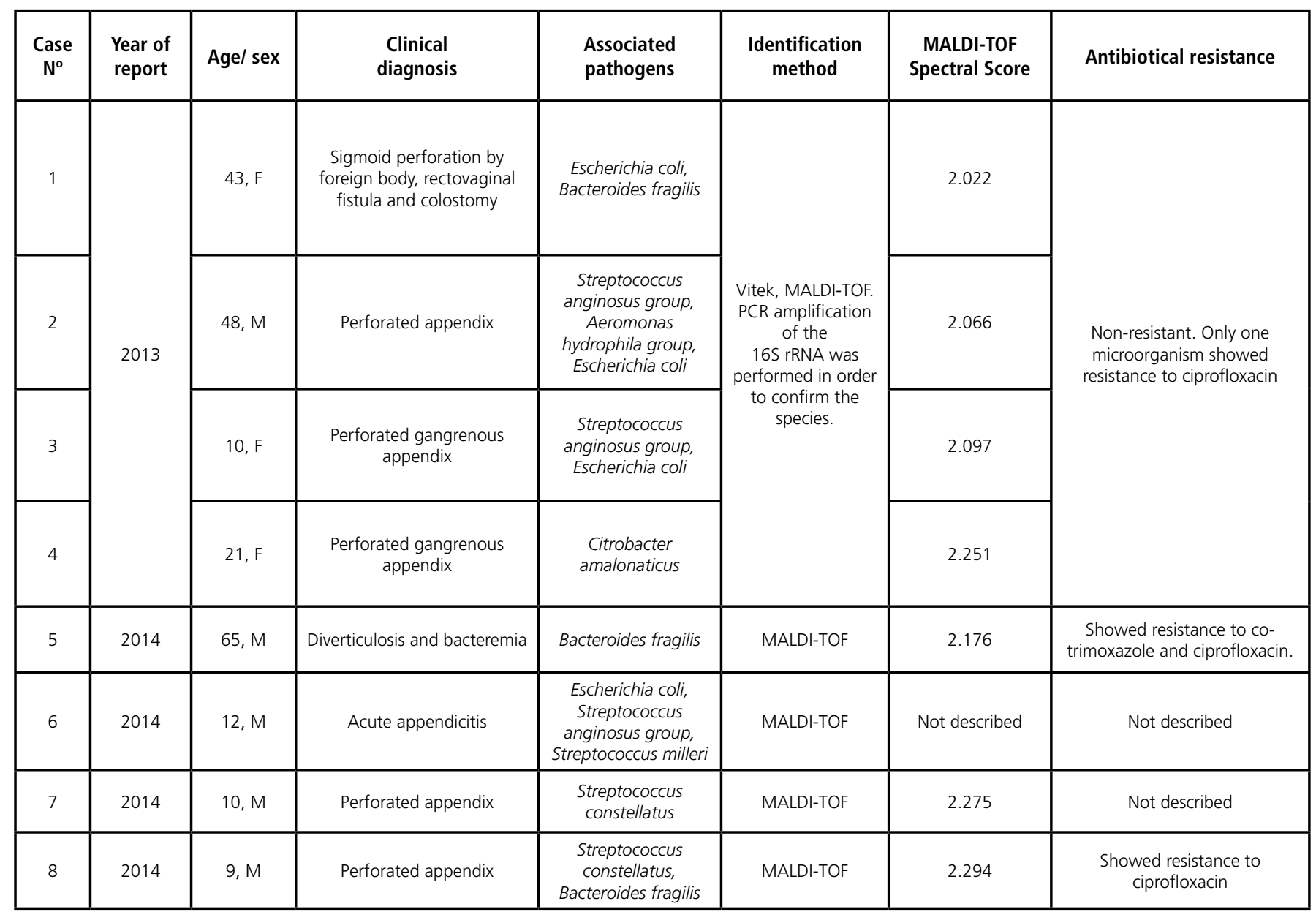




\begin{tabular}{|c|c|c|c|c|c|c|c|}
\hline 9 & 2017 & $54, \mathrm{~F}$ & Left psoas abscess & $\begin{array}{l}\text { Escherichia coli, } \\
\text { bacteroides fragilis }\end{array}$ & MALDI-TOF & \multirow{14}{*}{$\begin{array}{l}\text { Spectral scores } \\
\text { between } 2.021 \\
\text { and } 2.145\end{array}$} & \multirow{14}{*}{ Showed resistance to ampicillin } \\
\hline 10 & 2017 & $15, F$ & $\begin{array}{l}\text { Purulent peritonitis, } \\
\text { salpingitis }\end{array}$ & $\begin{array}{c}\text { Escherichia coli, } \\
\text { Streptococcus } \\
\text { anginosus, } \\
\text { Bacteroides fragilis }\end{array}$ & MALDI-TOF & & \\
\hline 11 & 2017 & $36, F$ & $\begin{array}{l}\text { Gangrenous acute } \\
\text { appendicits. Purulent } \\
\text { peritonitis. }\end{array}$ & Bacteroides fragilis & MALDI-TOF & & \\
\hline 12 & 2017 & $61, M$ & $\begin{array}{l}\text { Gangrenous acute } \\
\text { appendicits. Acute } \\
\text { peritonitis. }\end{array}$ & Escherichia coli & MALDI-TOF & & \\
\hline 13 & 2017 & $40, \mathrm{M}$ & $\begin{array}{c}\text { Gangrenous acute } \\
\text { appendicits. Acute } \\
\text { generalized peritonitis. }\end{array}$ & Escherichia coli & MALDI-TOF & & \\
\hline 14 & 2017 & $38, F$ & $\begin{array}{c}\text { Acute appendicitis, pelvic } \\
\text { abscess }\end{array}$ & Escherichia coli & MALDI-TOF & & \\
\hline 15 & 2017 & $18, F$ & $\begin{array}{l}\text { Gangrenous acute } \\
\text { appendicitis with perforated } \\
\text { base, generalized peritonitis. }\end{array}$ & $\begin{array}{l}\text { Streptococcus } \\
\text { viridans group }\end{array}$ & MALDI-TOF & & \\
\hline 16 & 2017 & $21, F$ & $\begin{array}{l}\text { Gangrenous appendicitis, } \\
\text { purulent peritonitis }\end{array}$ & $\begin{array}{l}\text { Citrobacter } \\
\text { amalonaticus }\end{array}$ & MALDI-TOF & & \\
\hline 17 & 2017 & $84, \mathrm{M}$ & Perforated apendicitis & Escherichia coli & MALDI-TOF & & \\
\hline 18 & 2017 & $32, \mathrm{M}$ & $\begin{array}{l}\text { Firearm wound, colon } \\
\text { perforation, faecal } \\
\text { peritonitis. }\end{array}$ & $\begin{array}{l}\text { Streptococcus } \\
\text { anginosus }\end{array}$ & MALDI-TOF & & \\
\hline 19 & 2017 & $19, \mathrm{M}$ & $\begin{array}{l}\text { Perforated appendicitis, } \\
\text { peritonitis }\end{array}$ & Escherichia coli & MALDI-TOF & & \\
\hline 20 & 2017 & $35, M$ & Peritonitis appendicular & Escherichia coli & MALDI-TOF & & \\
\hline 21 & 2017 & $67, M$ & $\begin{array}{l}\text { Purulent peritonitis, resulting } \\
\text { from perforated sigmoid }\end{array}$ & $\begin{array}{c}\text { Escherichia coli, } \\
\text { Streptococcus } \\
\text { viridans group, } \\
\text { Bacteroides fragilis. }\end{array}$ & MALDI-TOF & & \\
\hline 22 & 2017 & $63, M$ & $\begin{array}{l}\text { Diverticulum, appendicular } \\
\text { purulent peritonitis }\end{array}$ & Escherichia coli & MALDI-TOF & & \\
\hline 23 & 2017 & $31, M$ & $\begin{array}{l}\text { Acute perforated } \\
\text { appendicitis }\end{array}$ & Not described & $\begin{array}{c}\text { Vitek, MALDI-TOF. } \\
\text { PCR amplification } \\
\text { of the } \\
\text { 16S rRNA was } \\
\text { performed in order } \\
\text { to confirm the } \\
\text { species. }\end{array}$ & 1,815 & $\begin{array}{l}\text { Resistant to ciprofloxacin and } \\
\text { trimetoprim-sulfamethoxazole }\end{array}$ \\
\hline 24 & 2018 & $5, F$ & Urinary tract infection & Not associated & $\begin{array}{l}\text { VITEK-2, MALDI- } \\
\text { TOF }\end{array}$ & 2.134 & Resistan to ampicillin \\
\hline 25 & 2020 & $14, \mathrm{M}$ & $\begin{array}{l}\text { Perforated appendicitis, } \\
\text { peritonitis }\end{array}$ & Not associated & $\begin{array}{l}\text { PHOENIX, MALDI- } \\
\text { TOF }\end{array}$ & 2,83 & Not described \\
\hline
\end{tabular}




\begin{tabular}{|c|c|c|c|c|c|c|c|}
\hline 26 & 2020 & $28, \mathrm{~F}$ & Acute appendicitis & Escherichia coli & $\begin{array}{c}\text { PHOENIX, MALDI- } \\
\text { TOF }\end{array}$ & 2,87 & Not described \\
\hline 27 & 2020 & $29, \mathrm{M}$ & Acute appendicitis & Escherichia coli & $\begin{array}{c}\text { PHOENIX, MALDI- } \\
\text { TOF }\end{array}$ & 2,94 & Not described \\
\hline 28 & 2020 & $68, \mathrm{M}$ & Acute appendicitis & Escherichia coli & $\begin{array}{c}\text { PHOENIX, MALDI- } \\
\text { TOF }\end{array}$ & 2,98 & Not described \\
\hline 29 & 2020 & $16, \mathrm{~F}$ & Acute appendicitis & Escherichia coli & $\begin{array}{c}\text { PHOENIX, MALDI- } \\
\text { TOF }\end{array}$ & 2,91 & Not described \\
\hline 30 & 2020 & $16, \mathrm{~F}$ & Acute appendicitis & Escherichia coli & $\begin{array}{c}\text { PHOENIX, MALDI- } \\
\text { TOF }\end{array}$ & 2,80 & Not described \\
\hline
\end{tabular}

Table 1. Comparison of the diagnostic methodology, antimicrobial resistance and the different reported cases of Comamonas kerstersii from the literature.

\section{CONCLUSIONS}

The diagnosis of C. kerstersii, can be biased due to the lack of records in automated equipment databases, especially those of phenotypic identification.

Methods such MALDI-TOF, polymerase chain reaction and DNA sequencing, allow the correct identification of the different species of these microorganisms.

It is also possible that there have been no previous reports of infections caused by Comamonas species in Ecuador, despite their common distribution in the global environment.

With the previous data and discussion, arises the hypothesis that $C$. kerstersii infection, that it is a common environmental microorganism, and the practice between people of some places of Ecuador of consumption of nondrinking or unboiled water, could lead to the subsequent colonization of the digestive tract, for that we propose to carry out an environmental study of human drinking water.

\section{Collaborators}

The authors declare to have contributed in a similar way to the original idea (FCG); study or article design (FCG, $J \mathrm{LE})$, data collection and data analysis (FCG, JLE, CDC, $\mathrm{PVH})$; Drafting and revision of the draft (FCG, CVL, SBM) and writing of the article (FCG, SBM, SRG, JLE, CDC).

\section{REFERÊNCIAS}

1. Parrilla - Paricio P, Luján- Mompeán J, Hernández- Aguera Q. Apendicitis Aguda. Manual de la Asociación Española de Cirujanos. $2^{\circ}$ ed. Madrid: Médica Panamericana; 2011.

2. Sellars $H$, Boorman P. Acute appendicitis. Surgery. 2017;35(8):432-438. $\quad$ http://dx.doi.org/10.1016/j. mpsur.2017.06.002

3. Martin RF. Acute appendicitis in adults: Clinical manifestations and differential diagnosis. Uptodate [Internet]. 2018 [cited 10 October 2019]. Available from: https://www.uptodate.com/contents/acute-appendicitisin-adults-clinical-manifestations-and-differential-diagnosis

4. Ávila M, García-Acero M. Apendicitis aguda: revisión de la presentación histopatológica en Boyacá, Colombia. Rev Colomb Cir. 2015;30(2):125-30.

5. Bhangu A, Søreide K, Di Saverio S, Assarsson J, Drake F. Acute appendicitis: modern understanding of pathogenesis, diagnosis, and management. The Lancet. 2015; 386(10000):1278-1287. http://dx.doi.org/10.1016/ $\underline{\text { S0140-6736(15)00275-5 }}$

6. Almuzara M, Barberis C, Veiga F, Bakai R, Cittadini $R$, Vera- Ocampo $C$, et al. Unusual presentations of 
Comamonas kerstersii infection. NMNI. 2017;19:91-95. media/2663/m100ed29 sample.pdf http://dx.doi.org/10.1016/j.nmni.2017.07.003

7. Zhou Y, Ma H, Dong Z, Shen M. Comamonas kerstersii bacteremia in a patient with acute perforated appendicitis. Medicine. 2018;97(13):e9296. http://dx.doi.org/10.1097/ MD.0000000000009296

8. Almuzara M, Cittadini R, Vera -Ocampo C, Bakai R, Traglia G, Ramirez $M$, et al. Intra-Abdominal Infections Due to Comamonas kerstersii. J Clin Microbiol. 2013; 51(6):1998-2000. http://dx.doi.org/10.1128/JCM.00659$\underline{13}$

9. James P. Steinberg EM. Burd. Other Gram-Negative and Gram-Variable Bacilli, in Mandell, Douglas, and Bennett's Principles and Practice of Infectious Diseases (Eighth Edition), 2015. Available from: https://www.sciencedirect. com/topics/medicine-and-dentistry/comamonas

10. Jiang $X$, Liu W, Zheng B. Complete genome sequencing of Comamonas kerstersii 8943, a causative agent for peritonitis. Scientific Data. 2018;5(1):1-8. http://dx.doi. org/10.1038/sdata.2018.222

11. Biswas J, Fitchett J, O'Hara G. Comamonas kerstersii and the Perforated Appendix. J Clin Microbiol. 2014; 52(8):3134-3134. http://dx.doi.org/10.1128/JCM.0090914

12. Almuzara $M$, Cittadini $R$, Estraviz $M$, Ellis A, Vay C. First report of Comamonas kerstersii causing urinary tract infection. NMNI. 2018;24:4-7. http://dx.doi.org/10.1016/j. nmni.2018.03.003

13. Opota O, Ney B, Zanetti G, Jaton K, Greub G, Prod'hom G. Bacteremia Caused by Comamonas kerstersii in a Patient with Diverticulosis. J Clin Microbiol. 2013;52(3):10091012. http://dx.doi.org/10.1128/JCM.02942-13

14. CLSI. Performance Standards for Antimicrobial Susceptibility Testing; Twenty-Fifth Informational Supplement. CLSI document M100-S25. Wayne, PA: Clinical and Laboratory Standards Institute; 2015.

15. CLSI. Performance Standards for Antimicrobial Susceptibility Testing. 29th ed. CLSI supplement M100. Wayne, PA: Clinical and Laboratory Standards Institute; [Internet]. 2019; Available from: https://clsi.org/ 